\title{
Treatment of constitutional delay of growth and puberty with oxandrolone compared with growth hormone
}

\author{
A Buyukgebiz, P C Hindmarsh, C G D Brook
}

\begin{abstract}
The effects of oxandrolone or biosynthetic human growth hormone (r-hGH) on the growth of 26 boys with constitutional delay of growth and puberty were studied. Both regimens increased growth rate twofold, oxandrolone to a greater extent than $\mathbf{r}$-hGH. We conclude that oxandrolone is a more effective method of increasing growth rate in such children.
\end{abstract}

Constitutional delay of growth and puberty occurs in healthy adolescents whose height is reduced for chronological age but generally appropriate for bone age and the stage of pubertal development, both of which are usually delayed. Anabolic steroids, given in low doses, produce an acceleration in growth rate that is maintained when treatment is stopped, provided that the testicular volume is over $5 \mathrm{ml}^{1-3}$ Eventual height does not seem to be increased, but perhaps more importantly it is not compromised. ${ }^{1}$ Transient growth hormone insufficiency is a feature of constitutional delay of growth and puberty ${ }^{4}$ so growth hormone might be a more effective treatment in terms of eventual height. ${ }^{5}$

We have investigated the role of oxandrolone and growth hormone on the growth of 26 adolescents with constitutional delay of growth and puberty and compared the results at the end of one year.

\section{Patients and methods}

Twenty six boys with constitutional delay of growth and puberty (mean age 13.8 years) were randomly allocated to receive oxandrolone (Searle) in a dose of $2.5 \mathrm{mg}$ orally at night for three months $(n=15)$ or biosynthetic human growth hormone ( $\mathrm{r}-\mathrm{hGH}$ ) (Genotropin, Kabi) in a dose of 20 units $/ \mathrm{m}^{2} /$ week (nightly subcutaneous injections) for one year $(n=11)$. The patients were observed for one year before treatment and followed up for a further year. The oxandrolone group therefore received treatment for three months and had no treatment for nine months, whereas the r-hGH group had treatment for 12 months. The after treatment auxological data refer to measures made at the end of this 12 month period in both groups.

Standard anthropometric measurements were made at intervals of three months and bone age assessed before and after the follow up period. Pubertal staging was recorded at each clinic visit using the method of Tanner. ${ }^{6}$ The studies were approved by the Middlesex Hospital ethics committee, and informed consent was obtained. All data were expressed as standard deviation scores (SD scores) and results analysed by the Wilcoxon signed rank sum test and MannWhitney U test.

\section{Results}

The anthropometric measurements at the start of treatment and at the end of the subsequent year are shown in the table. All children fulfilled the criteria for the diagnosis of constitutional delay of growth and puberty with delayed bone age, normal height SD score for bone age, and delayed pubertal development. There were no significant differences between the groups before treatment (Mann-Whitney $\mathrm{p}>0.05)$

Both treatments resulted in significant increases in height velocity, from a pretreatment median value of $3.9 \mathrm{~cm} /$ year to $8.3 \mathrm{~cm} /$ year for the oxandrolone treated group (Wilcoxon $\mathrm{p}=0.01$ ), and from $3.8 \mathrm{~cm} /$ year to $6.8 \mathrm{~cm} /$ year for the r-hGH treated group (Wilcoxon, $\mathrm{p}=0.01$ ). The increment in height velocity induced by oxandrolone was significantly greater than that induced by growth hormone (median oxandrolone $4.4 \mathrm{~cm} /$ year; median $\mathrm{r}-\mathrm{hGH} 3.0 \mathrm{~cm} /$ year; Mann-Whitney $\mathbf{p}=0.02$ ). Pubertal advance was similar in both groups as shown by their similar testicular volumes at the end of the year.

\section{Discussion}

Growth delay associated with delayed puberty is
Endocrine Unit, Middlesex Hospital, Mortimer Street, London WIN 8AA

A Buyukgebiz

P C Hindmarsh

C G D Brook

Correspondence to: Professor Brook.

Accepted 27 November 1989
Anthropometric data of 26 adolescent boys_values are given as median (range)

\begin{tabular}{|c|c|c|c|c|}
\hline \multirow[t]{2}{*}{ Measurement } & \multicolumn{2}{|l|}{ Before treatment } & \multicolumn{2}{|l|}{ After treatment } \\
\hline & Oxandrolone & Growth hormone & Oxandrolone & Growth hormone \\
\hline $\begin{array}{l}\text { Chronological age (years) } \\
\text { Testicular volume (ml) } \\
\text { Height velocity (cm/year) } \\
\text { Height velocity increment } \\
\text { (cm/year/year) }\end{array}$ & $\begin{array}{c}13 \cdot 8(12 \cdot 1-15 \cdot 4) \\
5 \cdot 8(3 \cdot 0-8 \cdot 0) \\
3 \cdot 9(2 \cdot 6-5 \cdot 3)\end{array}$ & $\begin{array}{c}13.9(12 \cdot 1-15 \cdot 9) \\
4 \cdot 8(2 \cdot 0-8 \cdot 0) \\
3 \cdot 8(2 \cdot 0-5 \cdot 3)\end{array}$ & $\begin{array}{c}14 \cdot 8(12 \cdot 0-16 \cdot 6) \\
10 \cdot 0(6 \cdot 0-15 \cdot 0) \\
8 \cdot 3(6 \cdot 3-11 \cdot 1)\end{array}$ & $\begin{array}{c}15 \cdot 0(12 \cdot 2-16 \cdot 9) \\
10 \cdot 7(6 \cdot 0-15 \cdot 0) \\
6 \cdot 8(5 \cdot 1-9 \cdot 0)\end{array}$ \\
\hline $\begin{array}{l}\text { Bone age delay (years) } \\
\text { Height SD score for } \\
\text { bone age }\end{array}$ & $-2 \cdot 1(-4.3$ to -0.2$)$ & $-2.3(-5.1$ to -1.0$)$ & $-2 \cdot 2(-4.2$ to -0.4$)$ & $-3.0(-4.7$ to -1.2$)$ \\
\hline
\end{tabular}


common in boys and may cause deviant behaviour and severe psychological problems. Most of these boys do not require extensive endocrinological investigations, which may be misleading as a result of transient growth hormone insufficiency, but they do urgently need treatment for their delay in growth and puberty. ${ }^{4}$ Both oxandrolone and growth hormone produced acceleration of growth in boys with constitutional delay of growth and puberty without any difference in testicular volumes.

This increased height velocity is not a placebo effect ${ }^{2}$ nor can it be attributed to the boys' own spontaneous growth spurt, as this does not occur until a testicular volume of $12 \mathrm{ml}$ is reached. ${ }^{6}$ Only three of the boys receiving oxandrolone and two of those receiving r-hGH had testicular volumes of $12 \mathrm{ml}$ or more at the end of the year of follow up. The significant difference in height velocity increment between oxandrolone and growth hormone could be the result of the sustained effect of oxandrolone previously noted. ${ }^{1-3}$ It is certainly not that oxandrolone triggers the pubertal growth spurt, as both groups had similar testicular volumes of $(10 \mathrm{ml})$ at the end of the study. There was therefore no difference in the speed of the progression through puberty between the two groups.

We consider that growth hormone is not indicated for the management of delay in the onset of the pubertal component of the human growth curve, but whether longer periods of treatment (more than one year) with growth hormone in constitutional delay of growth and puberty would increase eventual height is still in question.

A Buyukgebiz was visiting research fellow from the University of Ankara. The study was supported by Kabipeptides, Stockholm.

1 Stanhope R, Brook CGD. Oxandrolone in low dose for constitutional delay of growth and puberty in boys. Arch Dis Child 1985;60:379-81.

2 Stanhope R, Buchanan CR, Fenn GC, Preece MA. Double blind placebo controlled trial of low dose oxandrolone in the treatment of boys with constitutional delay of growth and puberty. Arch Dis Child 1988;63:501-5.

3 Clayton PE, Shalet SM, Price DA, Addison GM. Growth hormone responses to oxandrolone in boys with constituhormone responses to oxandrolone in boys with constitu-
tional delay of growth and puberty (CDGP). Clin Endocrinol tional delay of grow

4 Eastman CJ, Lazarus L, Stuart MC, Casey JH. The effect of puberty on growth hormone secretion in boys with short stature and delayed adolescence. Aust NZ F Med 1971;1: $154-9$

5 Bierich JR. Treatment of constitutional delay of growth and adolescence with human growth hormone. Klin Padiatr 1986;195:309-16

6 Tanner JM. Growth at adolescence. Oxford: Blackwell, 1962.

\title{
Endotracheal compared with intravenous administration of atropine
}

\author{
R F Howard, R $M$ Bingham
}

\begin{abstract}
Endotracheal and intravenous administration of atropine were compared in two groups of 10 children. No differences were found between the groups in effect on heart rate or speed of onset of the effect. We conclude that the two methods are equally effective.
\end{abstract}

Giving drugs by the endotracheal route has been recommended for use in resuscitation when venous access is not immediately available. ${ }^{1}$ Atropine, adrenaline, and lignocaine have all been given in this way. ${ }^{2} 3$ Most of the supporting data come from animal studies, but recently doubt has been expressed about the plasma concentrations achieved in adults after drugs have been given by the endotracheal route. ${ }^{4} \mathrm{We}$ therefore investigated the effect of atropine given in this way to children, measuring changes in the heart rate after a bolus dose.

Department of

Anaesthesia,

Sick Children,

Great Ormond Street,

London WC1N 3JH

R F Howard

R M Bingham

Correspondence to:

Dr Bingham.

Accepted 8 November 1989

\section{Patients and methods}

Twenty children aged between 1 and 8 years undergoing routine anaesthesia that required endotracheal intubation and neuromuscular blockade (for peripheral orthopaedic or urological operations) were studied. Informed consent was obtained and the children were randomly allocated to receive either atropine $25 \mu \mathrm{g} / \mathrm{kg}$ (diluted to $2 \mathrm{ml}$ with $0.9 \%$ saline) intravenously and $2 \mathrm{ml} 0.9 \%$ saline endotracheally, simultaneously, or atropine $50 \mu \mathrm{g} / \mathrm{kg}$ (diluted to $2 \mathrm{ml}$ with $0.9 \%$ saline) endotracheally and $2 \mathrm{ml} 0.9 \%$ saline intravenously, simultaneously. Neostigmine $(50 \mu \mathrm{g} / \mathrm{kg}$ ) was given six minutes later to reverse the effect of the neuromuscular blockage.

Heart rate was monitored continuously using an electrocardiograph (Simonsen and Weel DS521) and recorded on a two channel paper chart recorder for 12 minutes after the atropine had been given. The endotracheal solution was given with a standard $2 \mathrm{ml}$ syringe without adaptation and was followed by five manual hyperinflations of the chest. The intravenous solution was given through an indwelling cannula in the hand or arm.

Table 1 Comparability of the groups. Values are expressed as mean (SEM) except where otherwise stated

\begin{tabular}{lcc}
\hline & $\begin{array}{l}\text { Intravenous } \\
\text { group }(n=10)\end{array}$ & $\begin{array}{l}\text { Endotracheal } \\
\text { group }(n=10)\end{array}$ \\
\hline F:M ratio & $4: 6$ & $5: 5$ \\
Age (years) & $4(0 \cdot 8)$ & $3 \cdot 4(0 \cdot 9)$ \\
Weight (kg) & $15 \cdot 8(2 \cdot 3)$ & $15 \cdot 4(2 \cdot 5)$ \\
\hline
\end{tabular}

